Euskal ikerketen aldizkaria | Revue d'études basques |

Revista de estudios vascos | Basque studies review

19 | 2016

Numéro XIX

\title{
Frantses eskoletan euskaraz mintzatzearen debekuaz
}

Jean-Baptiste Coyos

\section{OpenEdition}

Journals

Édition électronique

URL : https://journals.openedition.org/lapurdum/3288

DOI : 10.4000/lapurdum.3288

ISSN : 1965-0655

Éditeur

IKER

Édition imprimée

Date de publication : 1 janvier 2016

Pagination : 177-184

ISBN : 978-2-95534-134-6

ISSN : $1273-3830$

Référence électronique

Jean-Baptiste Coyos, «Frantses eskoletan euskaraz mintzatzearen debekuaz», Lapurdum [Linean], 19 | 2016, Sarean emana----an 01 janvier 2021, kontsultatu 03 septembre 2021. URL: http:// journals.openedition.org/lapurdum/3288 ; DOI: https://doi.org/10.4000/lapurdum.3288 


\section{Frantses eskoletan euskaraz mintzatzearen debekuaz}

Jean-Baptiste COYOS

IKER UMR 5478

\section{Sarrera ${ }^{1}$}

Artikulu xume honetan usu aipatu den eskoletan euskaraz mintzatzearen debekuaz azalduko da. Ikerketa txiki honen iturriak lekukotasunak dira, frantses eskoletan izan diren eta 1921. urtearen eta 1954. urtearen artean sortu diren hiztunen lekukotasunak ${ }^{2}$. Lekuko horiek ez dira euskaldun arruntak. Gehienak euskaldun zahar izanik, beren bizian okzitaniera, gaskoi edo bearnes forman, ikasi dute. Oro har hirueledun dira edo ziren, frantsesa ere, usuenik eskolan, ikasi baitzuten. Euskal hirueledun izendatuko ditut. Okzitaniera ama-hizkuntza izan duten hirueledunak edo frantsesa ama-hizkuntza izanik okzitaniera euskara baino lehen ikasi dutenak okzitaniar hirueledun izendatuko ditut.

Euskal hirueledun lekuko horien gehiengoa euskara eta okzitanieraren arteko ukipen eremuan sortua da. Hona mendebaldetik ekialdera, Ipar Euskal Herriko iparrean eta

1. Lan honek Hiruele proiektuari zor dio. Hiruele ikerketak "euskara eta gaskoinaren arteko ukimen eremu tradizionalean aurkitzen diren hiztun elebidun (euskara-frantsesa) eta hirueledunen (euskara-frantsesa-okzitaniera) hizkerak eta hizkuntzari buruzko burubideak (errepresentazioak, jarrerak, oroitzapenak, beren hizkuntzen bilakaerari buruzko gogoetak)" aztertzen ditu (http://www.iker.cnrs.fr/-hirulele-.html?lang=eu). Baliatuko ditudan datuak eta aipamenak Hiruele proiektuaren markoan grabatu diren elkarrizketetan hartuak dira. Eskerrak eman nahi dizkiet Hirueleren parte hartzaile deneri: Ricardo Etxepare zuzendaria, Yvan Bareyre, Philippe Biu, Jasone Salaberria, Alain Viaut eta Xarles Videgaini berari.

2. Lekukoen izena eta abizena ez ditugu emanen, adina, sorgunea edo bizigunea bakarrik, konfidentzialtasunarengatik. Irakasleenak ez ere. Datuak 2013. urtearen eta 2014. urtearen artean bilduak izan dira. Lekukoaren adina emaiten dugunean bilketaren urtea kontuan hartua da. 
Biarnoan, eremu horko sorterrien zerrenda: Bardoze (Lapurdi), Aiherra, Oragarre, Arrueta, Ilharre (Nafarroa Beherea), Ürrüstoi, Barkoxe, Eskiula, Montori (Zuberoa), Landa, Aramitze, Inhasi (Baretos ibarra, Biarno) (euskal eta okzitaniar hirueledunen sorterrietako mapa ${ }^{3}$ ikus artikuluaren bukaeran). Batzuetan herri horietako auzogune bat bakarrik da ukipen gunea. Holakoak dira adibidez Oragarreko Bartak auzogunea, Ilharreko Egipto auzogunea, Landako Gaztelondo auzogunea, Aramitzeko Narbe auzogunea edo Inhasiko Narbe auzogunea. Lapurditik Biarnorako lurralde berezi horretan sortuak, bi hizkuntzak haurtzaroan jadanik gutxi edo aski entzuten zituzten lekuko horiek, euskara lehen hizkuntza izanik.

Aztertu den lagin hori murritza da, hogeita hamar bat euskal hirueledun. Ondorioz, euskaraz mintzatzearen debeku horrez ateratuko diren ondorioak ez dira behar bada adierazgarriak izanen, frantsesa eskolan ikasi duten euskaldun zahar anitz aztertuko lituzkeen inkesta erraldoi batenak liratekeen bezala. Halere, ikusiko dugun bezala, lekukotasun eta datu interesgarriak ekartzen dizkigu.

Hiztun berezi horien lekukotasunei mugatuko zaie lana, lekukoen hitzei. Lekukotasunen testuingurua ez da aztertuko, garai hartako Hezkuntza nazionalaren zuzentarauak edo gomendioak euskarari buruz ${ }^{4}$, irakasleen ikusmoldea, gurasoen jarrera eta irudikapenak frantses eskolari buruz, etab.

\section{Inkestaz eta hirueletasunaz bi hitz}

Hiruele proiektuaren zati soziolinguistikoan inkesta bidez lekukoak hiru hizkuntzak noiz, nola ikasi dituen aztertzen da, haurtzaroan edo helduaroan, norekin baliatu eta baliatzen dituen familian, eskolan, elizan, lanean, aisialdietan, zer pentsatzen duen hizkuntza horiez, hirueledun izanez bere burua nola ikusten duen, besteak beste. Ikasketak aipatzen direlarik, inkestatzaileak lekukoari frantses eskolara noiz joan zen galdatzen dio (ikastolarik edo irakaskuntza elebidunik ez baitzen orduan). Eta lekukoak euskaraz mintzatzen zenetz adierazten ez badu, galdatzen dio inkestatzaileak. Orduan usuenik lekukoak zer zen irakaslearen jarrera eta zigorrik bazenetz aipatzen du. Beraz mintzagai hori bat baizik ez da beste anitz artean elkarrizketan eta lekukoa ez da horrez luzaz mintzatzen.

Hirueleduntasuna biziki ezberdina izan daiteke, baina era batez edo bestez, lekuko horiek denek gutxi gorabehera hiru hizkuntzak menperatzen edo menperatu dituzte beren bizian zehar. Batzuek hizkuntza bat edo bestea ahantzi dute, baliatzen ez baitute. Halere ulermena atxiki dute.

Lehen hizkuntza familian bistan da ikasi dute, bigarrena, frantsesa, eskolan. Ohar gaitezen kasu berezi horrez: Montoriko bi anaiak euskara eta bearnesa izan dituzte lehen-hizkuntzatzat (euskara amarenganik eta bearnesa aitarenganik). Hirugarren hizkuntza ikasteko

3. 'Mapa hori Iker zentroko Jasone Salaberriak prestatu du. Milesker hari.

4. Frantzian eskola-irakaskuntza zinez zentralizatua zen eta da oraino. Tokiz toki ezberdintasun zonbait baldin baziren ere, Hezkuntza nazionalak indar handiak egiten zituen eskola-sistema bateratzeko, berdintzeko. Eskualdeetako hizkuntzak oztopo handia ziren berdintzeko mugimendu horren aitzinean, frantsesa inposatzeko eskola esparrutik desagertu behar zituzten. 
edo bederen ikastea hasteko era ezberdinak izan dira: haurtzaroko auzoekin, haurtzaroko adiskideekin, aitaren edo amaren familian, aprendizgoan, lanean, senarra edo emaztearekin, senarraren edo emaztearen familian. Halere batzuek hirugarren hizkuntza, euskara edo okzitaniera, helduaroan helduentzako ikastegian ikasi dute, beren kabuz. Guti dira holakoak.

Ikus dezagun orain hobeki nola inkestan euskaraz mintzatzearen debekua agertzen zen. Inkestagileak lehenik inkestatuaren haurtzaroa aztertzen zuen galdera zonbaiten bidez, inkestatua libreki mintzatzen uzten. Halere galdera nahitaezkoak baziren: adina, sorterria, amaren eta aitaren hizkuntza(k), aitatxi eta amatxiena(k), zertaz mintzatzen zen etxen, norekin, auzogunean, elizan eta beraz eskolan. Maizenik eskolara joateko unean euskal hirueledun horiek frantsesa ez zakiten batere, edo hitz gutxi haurride lehenak ikasirik. Eta denek hori azpimarratzen dute, zailtasun hori, ikasgelan dena frantsesez baitzen. Aldiz haur zigortuen sofrimendua eta traumatismoa ez dituzte hanitx aipatu, ez ere beste ikasleen usteak. Inkestagileak ez zuen puntu hori sakontzen. Haatik, inkestatuak eskolan nola iragaten zen kontatzen zuelarik eta zigorrak ez baldin bazituen aipatzen, inkestagileak galdatzen zion bazirenetz. Baina ez gehiago.

Beraz, oro har, inkestatuak libre izan ziren debekuari eta zigorrari buruz nahi zutena kontatzeko eta zigorra bera azpimarratu dute bereziki. Nolakoa zen. Halere ahots-tonuak erakusten zuen nola zigor horiek gogor zirela haurrentzat, zigorra bazen kasuan bistan da.

\section{Euskal hirueledunen debekuari buruzko lekukotasunak}

Baliatuko ditugun lekukotasunak ez dira denak hirueledunenak. Batzuetan elkarrizketan bikotekidea, elebidun bakarrik izanez, euskaraz mintzatzearen debekuaz eskoletan zerbait baliagarri erran dezake eta baliatuko dugu. Beste salbuespen da amahizkuntza gaskoia duen emazte hori, eskolako adiskideekin euskara pixka bat ikasi duena eta zigortua izan zena. Bestalde, euskal hirueledun denak ez dira joan Iparraldeko frantses eskolara. Ilharreko (Nafarroa Beherea) Egipto auzoguneko bi lekuko Burgueko eskolara joan ziren, gaskoi lurraldera beraz, hurbilago baitzen. Azkenik, lekuko batek jolasaldian haurrak euskaraz mintzatzen zirela erraten du baina ikasgelan nola iragaten zen ez da oroitzen. Debekurik edo zigorrik bazenetz errateko ez da gai. Erran behar da lekukoak maizenik adinekoak direla eta oroitzapenak ez direla beti argi. Aldiz, batzuentzat zinez argiak dira, memorian grabatuak.

Beraz, salbuespen horiek denak kontuan ez hartuz, oro har 26 lekukotasun baliatuko ditugu. Lekukoak sorterriaren arabera aurkeztuko dira, Ipar Euskal Herriko mendebaldetik ekialdera, sorterriko eskolan eskolatuak izan baitira usuenik. Lekukotasun bakoitzari zenbaki bat emana zaio.

Lehen oharra da euskara baliatzea eskolan ez zela beti zigortua. Has gaitezen debekurik eta zigorrik gabeko lekukotasunekin.

3.1. Debekurik eta zigorrik gabeko lekukotasunak: 7

1. Bardozen (Lapurdi) sortu eta han berean bizi den 72 urteko gizon batek (2014) zigorrik ez zela erraten du Bardozeko eskolan. Aldiz 20 bat urte lehenago bazen (ikus 13. lekukotasuna beherago).

2. Oragarren (Nafarroa Beherea) sortu eta Bastidan (Nafarroa Beherea) bizi den 82 urteko emazte batek (2014) zigor oroitzapenik ez du Oragarreko eskolan. 
3. Oragarren (Nafarroa Beherea) Bartak auzogunean sortu eta Arruetan (Nafarroa Beherea) bizi den 81 urteko gizon batek (2014) Bartetako eskola publikoan zigorrik ez zela erraten du.

4. Oragarren (Nafarroa Beherea) Bartak auzogunean sortu eta Baionan (Lapurdi) bizi den 75 urteko gizon batek (2014) zigor oroitzapenik ez du Bartetako eskolan. Entzun du beste nonbait, zigortzeko, "xirri" bat iraganarazten zutela.

5. Arruetan (Nafarroa Beherea) sortu eta Akamarren (Bidaxuneko eskualdea) bizi den 71 urteko gizon batek (2014) zigor oroitzapenik ez du Arruetako eskola publikoan.

6. Altzain (Zuberoa) sortu eta Urdiñarben (Zuberoa) bizi den 66 urteko gizon batek (2014) zigor oroitzapenik ez du Altzaiko Saint-Louis de Gonzague eskola pribatuan. Alderantziz ere, bi apez irakasleetarik batek ikasleei pastoral bat euskaraz eginarazi zien. Arratsaldeetan ere La Fontaineren alegiak euskaraz ikasi zituzten Madalena de Jauregiberri euskaltzalearekin.

7. Montorin (Zuberoa) sortu eta Landan (Baretos ibarra, Biarno) bizi den 73 urteko emazte batek (2014) Montoriko eskolan zigorrik ez zela erraten du. «Ez han, seküla ». Orduan euskara ulertzen zuen baina ez zen mintzatzen.

\subsection{Debekua baina zigorrik gabeko lekukotasunak: 5}

8. Ilharren (Nafarroa Beherea) sortu eta Akamarren (Bidaxuneko eskualdea, Nafarroa Beherea) bizi den 64 urteko emazte batek (2014) zigor oroitzapenik ez du Ilharreko eskolan. Baina eskolan oroitarazten zieten euskaraz ez zutela mintzatu behar. Frantses hitz bat ere ez zuen ezagutzen eskolan sartzean.

9. Eskiulan (Zuberoa) sortu eta Estòs/Eztoze (Biarno) bizi den 90 urteko gizon batek (2013) euskaraz mintzatzea debekatua zela erran du Eskiulako eskolan. Baina zigorrik ez zen. Erakasleak "Lehen hezkuntza bukaeraren ikasketen agiria" (Certificat de fin d'études primaires) eskura zezaten nahi zuen.

10. Montorin (Zuberoa) sortu eta sortetxean bizi den 85 urteko gizon batek (2013) euskaraz edo bearnesez mintzatzea debekatua zela erran du Montoriko eskolan. Baina zigor oroitzapenik ez du.

11. Bere anaiak bezala, Montorin (Zuberoa) sortu eta Montorin bizi den 91 urteko gizonak (2013) euskaraz edo bearnesez mintzatzea debekatua zela erran du Montoriko eskolan. Zigorrik ez zen baina irakaslearen gaitzespenak bai.

12. Inhasin (Baretos ibarra, Biarno) Narbe auzogunean sortu eta Inhasin bizi den 58 urteko gizon batek (2014) zigor oroitzapenik ez du Eskiulako eskolan (Inasiko Narbe auzogunearendako eskola zen). Baina ez zen euskaraz mintzatu behar. « Eta ez ginizün frantsesa ezagützen! » azpimarratzen du.

\subsection{Debekua eta zigorra: 14}

13. Bardozen (Lapurdi) sortu eta han berean bizi den 93 urteko gizon bat (2014) zigorraz oroitzen da Bardozeko eskolan. Hola iragaten zen: Euskaraz mintzatzen zenak herriko plazan oren batez egon behar zuen pankarta batekin bizkarrean. Pankarta horretan hori idatzia zen: «Je ne parlerai plus en basque « Ez naiz gehiago euskaraz mintzatuko ». Iragaten zen jendeak irakurtzen zuen zer zen markatua. 
Mintzazen ziren denak zigortuak ziren. Lekukoa ohartzen da: «Ez zuan beldurra errientak! ». Aldiz, « Lehen hezkuntza bukaeraren ikasketen agiria » eskuratzeko azterketan Bidaxunen, Jean Baptiste Elizanbururen Ikusten duzu goizean kantua eman izan behar zuen lekukoak.

14. Aiherran (Nafarroa Beherea) sortu eta Bastidan (Nafarroa Beherea) bizi den 82 urteko emazte bat (2014) zigorraz oroitzen da Aiherrako eskola pribatuan (nesken eskola zen). Euskaraz mintzatzen zena zokora joaten zen murru baten ondoan eta batzuetan leiho gabeko gela ilun batera istant batez.

15. Aiherran (Nafarroa Beherea) sortu eta Akamarren (Bidaxuneko eskualdea, Nafarroa Beherea) bizi den 67 urteko emazte bat (2014) zigorraz oroitzen da Aiherrako nesken eskolan. Zigorra euskaraz errana zen erranaldia 100 aldiz frantsesez idaztea zen. Halere, euskaraz idatzi zuen testu batekin bigarren saria eskuratzeaz oroitzen da. Beraz euskarak leku bat bazuen eskola hartan.

16. Izpuran (Nafarroa Beherea) sortu eta Izorran (Baretos ibarra, Biarno) bizi den 70 urteko gizon bat (2013) zigorraz oroitzen da Izpurako eskolan. Kanpoan jolaslekuan bi zutoin eta bi platanondo baziren. Euskaraz mintzatzen harrapatua zena lehen zutoinara zihoan. Besteak elkarren ondoan zihoazten beste hiru gune libreetara eta bosgarren bat baldin bazen lehenaren lekua hartzen zuen. Halere, lekukoaren arabera, axolarik ez zen beretzat frantsesaren eta euskararen artean.

17. Arruetan (Nafarroa Beherea) sortu eta han bizi den 76 urteko emazte bat (2014) zigorraz oroitzen da Arruetako eskolan. Emazte horrek gaskoia zuen lehen hizkuntza, baina adiskideekin euskara ikasi zuen pixka bat. Behin irakasleak euskaraz mintzatzen harrapatu zuen eta 500 aldiz « Je ne parlerai pas en basque en classe » "Gelan ez naiz euskaraz mintzatuko » erranaldia kopiatu zuen.

18. Ilharren (Nafarroa Beherea) sortu eta Mitikilen (Zuberoa) bizi den 85 urteko gizon bat (2013) zigorraz oroitzen da Ilharreko eskolan. Ez zen euskaraz mintzatu behar. « Ixilka» mintzatzen ziren. Erakasleak kopiatzeko lerroak ematen zituen.

19. Oihergin (Zuberoa) sortu eta Lixozen (Biarno) bizi den 87 urteko emazte bat (2014) zigorraz oroitzen da Oihergiko eskolan. Zigor idatzirik ez zen. Euskaraz mintzatzen zena zokora joaten zen xutik.

20. Lexantzün (Zuberoa) sortu eta Eretan (Baretos ibarra, Biarno) bizi den 84 urteko gizon bat (2014) zigorraz oroitzen da Lexantzüko eskolan. Euskaraz mintzatzen zuenak jolasaldian belauniko egon behar zuen.

21. Urrüstoin (Zuberoa) sortu eta sortetxean bizi den 76 urteko gizon bat (2014) zigorraz oroitzen da Urrüstoiko eskolan. Euskaraz mintzatzen zenak 50 aldiz « Je ne parlerai pas en basque » "Ez naiz euskaraz mintzatuko » erranaldia kopiatu behar zuen. Gaskoia zuen lehen hizkuntza eta euskara eskolako adiskideekin hasi zuen ikasten. « Gordailüz eüskaraz » mintzatzen ziren.

22. Barkoxen (Zuberoa) sortu eta Gotainen (Zuberoa) bizi den 79 urteko gizon bat (2013) zigorraz oroitzen da Barkoxeko eskolan. Euskaraz mintzatzen zenak eskolako giltza bazuen eta oren bat gehiago egoten zen. Zigorra zen baina irakasleak une hori baliatzen zuen zigortua zenaren eskola hutsuneak lantzeko.

23. Eskiulan (Zuberoa) sortu eta han bizi den 72 urteko gizon bat (2014) zigorraz oroitzen da Barkoxeko eskolan. Euskaraz mintzatzen zenak klera puska bat ahoan bazuen. Azken zuena zigortua zen arratsean; kadira eta bankuak garbitu behar 
zituen eta gela erraztatu.

24. Landan (Baretos ibarra, Biarno) sortu eta sortetxean bizi den 59 urteko gizon bat (2014) zigorraz oroitzen da Barkoxeko eskolan (eskola hurbilena). Euskaraz mintzatzen zenak jolasaldian belauniko egon behar zuen jolaslekuko zoko batean.

25. Aramitzen (Baretos ibarra, Biarno) sortu eta Oloruen (Biarno) bizi den 61 urteko gizon bat (2013) zigorraz oroitzen da Eskiulako Narbe auzoguneko eskolan (eskola hurbilena). Euskaraz mintzatzen zuenak « bons points $»^{5}$ " puntu onak » galtzen zituen.

26. Aramitzen (Baretos ibarra, Biarno) sortu eta sortetxean bizi den 82 urteko emazte bat (2014) zigorraz oroitzen da Eskiulako Narbe auzoguneko eskolan (eskola hurbilena). Euskaraz mintzatzen zenak ontzi txiki bat bazuen, « bueita ttipiñi bat », eta azken zuenak eskolan egon behar zuen besteek baino berantago. Jolasaldirik ez zuen ere.

\section{Okzitaniar hirueledunek}

Hiruele proiektuan bearnes edo gaskoi lekuko zonbait aztertu dira ere, horiek okzitaniera ama-hizkuntza izanik frantsesa eta euskara ikasi dituzte edo frantsesa amahizkuntza izanik okzitaniera eta ondotik euskara ikasi dituzte. Gutxi dira, sei, baina batzuetan bikotekidearen lekukotasuna izan dugu ere.

Euskaraz mintzatzearen debekuaz mintzatu ondoan, so egin dezakegun beraz nola iragaten zen Biarnoan eta Bidaxuneko eskualdean. Okzitaniar hirueledunak ez dute zigorrik aipatzen euskal hirueledunek aipatu duten bezala. Halere, lekuko batek, Montorin sortu eta han bizi den 85 urteko emazte batek (2014), kontatzen du nola bearnesez mintzatzea debekatua zen (10. eta 11. lekukotasunak ikus ere). Haatik irakasle batek ikasleei erraten zien bearnesa baliagarria izanen zela frantses hitz amaiera batzuk ezagutzeko. Beste irakasle bat, aldiz, bidera ere joaten zen ikasleak frantsesez edo bearnesez mintzatzen zirenetz entzutera.

Lekuko baten senarrak, elebidun eta gaskoia lehen-hizuntzatzat duenak, kontatzen du nola Akamarreko (Bidaxuneko eskualdea) eskolako jolaslekuan gaskoiez mintzatzen zenak hiru koloretako (frantses banderako koloreak) zur puska txiki bat hartzen zuen. Egunean azken zuena oren laurden bat gehiago egoten zen eskolan. Baina lekukotasunak denak kontuan hartuz salbuespena da hori.

\section{Ondorioak}

Hogeita sei euskal hirueledunen lekukotasun horietarik zer atera dezagun? Horien hitzei mugatuz, hona gogoeta batzuk.

5. «Bons points » delakoak paper zati inprimatu txikiak ziren ikasleak zerbait ongi egiten zuenean erakasleak emaiten zizkionak zoriontzeko. 


\subsection{Zenbaki gordinak}

Oro har euskaraz mintzatzea eskola barnean ez zen orduan onartua. Aztertzen den garai hori Bigarren Mundu Gerla baino hamar urte lehenago hasten da eta gerla horren bukaera baino hogei urte berantago bururatzen da.

Hain zuzen, hogeita sei lekukotasunetarik hemeretzi debeku aipamen baditugu (26/19). Ondorioz erran dezakegu debekua sistematikoa ez zela, baina bai aski hedatua. Hemeretzi debeku horietarik hamalau dira kontatzen zigor batekin (19/14). Beraz eskolan debekua indarrean baldin bazen, zigorra kasik sistematikoa zela erran daiteke. Zenbakien aztertzea bukatzeko, hogeita sei lekukotasunetarik hamalau zigor, erdia baino gehixeago, zerrendatzen da (26/14).

Ez dakigu lan honetan baliatu den lagin hau zinez adierazgarria den, baina, hain segur, euskaraz mintzatzea eskola barnean ez zela onartua baieztatzen ahal da.

\subsection{Zigorren aniztasuna eta bilakaera denboran zehar}

Zigorrak ezberdinak ziren, irakaslearen arabera. Horrek erran nahi luke Hezkuntza nazionalak edo tokiko ikuskariak zigor motari buruzko gomendiorik ez zutela ematen. Irakasleen irudimena emankorra zen zigorrak asmatzeko.

Hona zigor motak: Herriko plazan egotea pankarta batekin bizkarrean (13. lekukotasuna), ikasgelako zokoan egotea (14.a, 19.a), zuhaitz ondoan egotea (16.a), gela berezi batean egotea (14.a), ikasgelan egotea jolasaldirik gabe (26.a), belauniko egotea (20.a, 24.a), garbiketak egitea ikasgelan (23.a), ikasgelan egotea eskola-lanak egiteko (22.a), lerro ainitz kopiatzea, 50 lerrotarik 500etara (15.a, 17.a, 18.a, 21.a), " puntu onak» galtzea (25.a).

Kopiatzeko zen erranaldi hedatuena edo bizkarrean eman zena hori zen: «Ez naiz (gehiago) euskaraz mintzatuko », baina frantsesez. Argia da eskolan haurren euskaraz mintzatzearen desagertaraztea zela helburu. Beste kopiaketa mota zen ikasleak euskaraz erran zuena frantsesez idaztea.

Zigor batzuek helburu pedagogikoak izan zitzaketen. Baina lekukotasun bat baizik ez dugu, 22.a Barkoxen. Irakasleak zigor orena baliatzen zuen zigortua zenaren eskola hutsuneak hobetzeko.

Kasu zonbaitetan euskaraz mintzatzen zirenak denak zigortuak ziren. Besteetan mintzatzen zen azkenak marka bat zuen eta ondotik berriz euskaraz mintzatzen zen beste bati ematen zion. Lekukotasunetan hiru marka ezberdin badira: eskolako giltza (22.a), klera puska bat (23.a), ontzi txiki bat (26.a).

Denborarekin zigorra aldatzen dela ohartzen da. Eskola berdinean zigorra aldatzen zen, Aiherrako nesken eskolaren kasuan adibidez (14. eta 15. lekukotasunak), edo desagertzen zen ere, eskola-maisua aldatzen baitzen. Bardozeko eskolaren kasua da, 1. eta 13. lekukotasunak parekatuz hogei urte berantago. Denborarekin haurrak euskaraz gutiagoa mintzazen zirela ohartzen da, Bardozen berriz. Montoriko eskolako kasuan ere, 20 urte berantago debekua desagertu zen (7.a, 10.a eta 11.a). Montorin debekua bikoitza zen, euskaraz edo bearnesez mintzatzearena. 
184

\subsection{Azken hitza}

Hiruele proiektuaren kuadroan bildu diren elkarrizketak biziki aberatsak dira. Hemen proposatu den euskaraz mintzatzearen debekuari buruzko azterketa lekukoen hitzei mugatu zaie. Elkarrizketan ikergai horrek leku gutxi hartzen zuen; inkestatzailearen galdera bat edo bi izan ziren inkestatuak berak gai hori aipatzen ez zuenean. Beraz urrunago joateko, euskal hirueledun horiekin gaia berriz lantzeko litzateke.

Dena den hogeita hamar hamarkadatik hirurogei hamarkadara Ipar Euskal Herriko iparraldeko eskolan euskaraz mintzatzea ez zen onartua. Debekua eta zigorrak aski zabalduak ziren eta mota ezberdinetakoak, eskola-maisuaren hautuaren arabera. Besteen artean, tresna eraginkorra izan zen debekua euskararen erabilera ahultzeko eta batzuetan desagertarazteko.

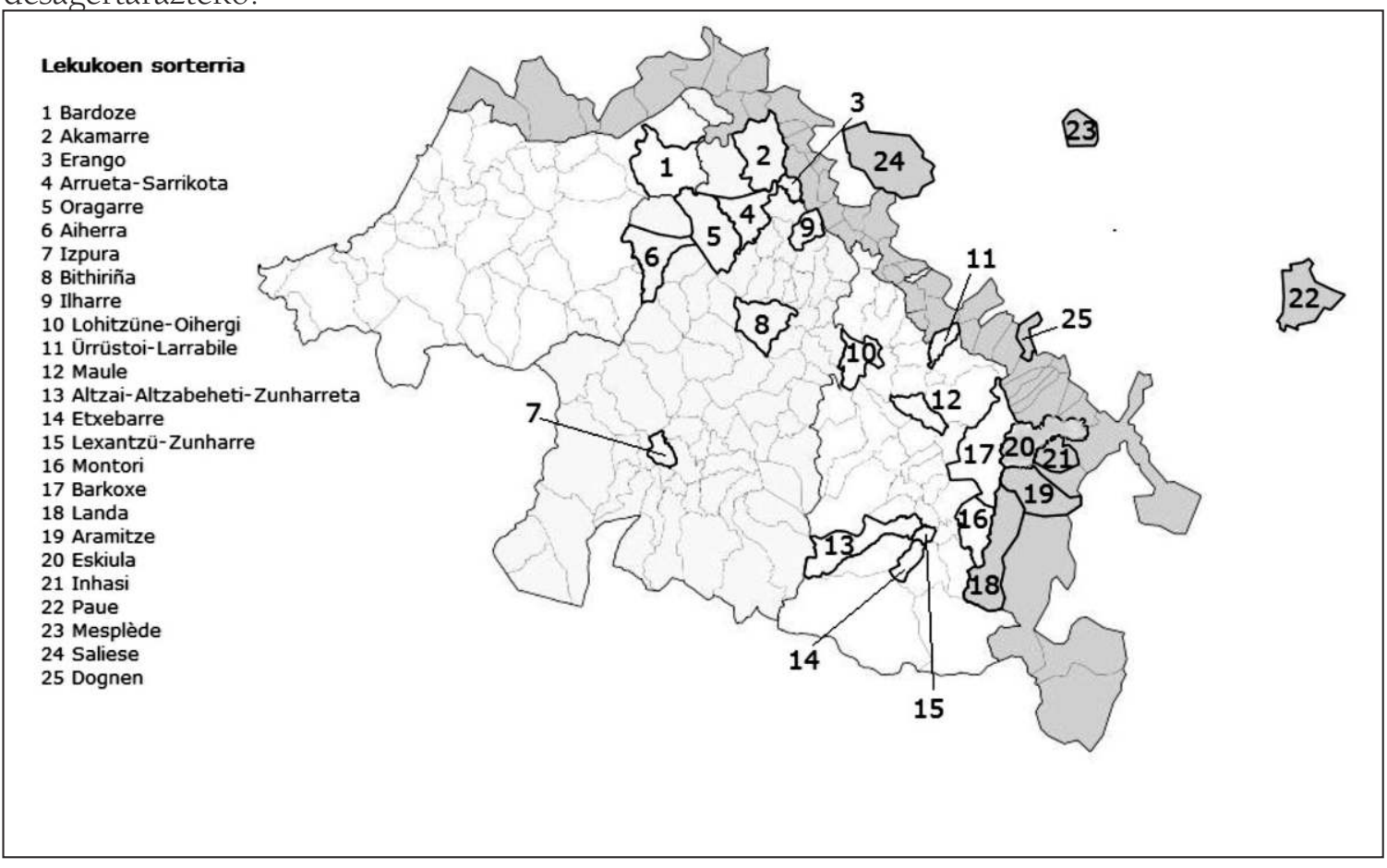

